\section{Review Article}

Ann Liver Transplant 2021;1(1):48-57 https://doi.org/10.52604/alt.21.0010

Check for updates
ALT

pISSN 2765-5121

eISSN 2765-6098

\title{
Living donor liver transplantation-associated retransplantation in adult patients
}

\author{
Deok-Bog Moon, Shin Hwang, Chul-Soo Ahn, Tae-Yong Ha, Gi-Won Song, \\ Dong-Hwang Jung, Gil-Chun Park
}

Division of Hepatobiliary Surgery and Liver Transplantation, Department of Surgery, Asan Medical Center, University of Ulsan College of Medicine, Seoul, Korea

Adult-to-adult living donor liver transplantation (LDLT) has been established as a successful alternative to help solve the serious shortage problem of deceased donor (DD) grafts. LDLT-associated retransplantation has been much less frequently performed than DD liver transplantation-associated retransplantation due to lower incidence of primary nonfunction, advance in surgical technique for LDLT, and organ shortage for retransplantation. Common causes of retransplantation include immunologic rejection, primary nonfunction or severe dysfunction, biliary complications, recurrence of primary disease and vascular complications. LD-associated retransplantation can be classified into three types according to the sequences of the grafts used: LD-to-LD, LD-to-DD, and DD-to-LD because different surgical techniques should be considered according to the different sequences. They are also re-classified into two types according to the retransplantation timing: early and late. The most typical type of LDLT-associated retransplantation is early LD-to-DD retransplantation. Any cause of early graft failure can be indicated for this type of retransplantation if a DD organ is available. For early LD-to-LD retransplantation, the type of second liver graft and hepatic arterial inflow source should be considered prudently. Early DD-to-LD retransplantation has been usually applied to primary non-function of the first DD liver graft. Late LD-to-LD or DD-to-LD retransplantation is not recommended because of heavy adhesion and anatomical distortion. The outcome of LDLT-associated retransplantation appears to be inferior to that of DDto-DD retransplantation. There are several technical limitations. Procurement of a LD liver graft with long vascular stumps is not allowed. Thus, alternative methods of vascular reconstruction are often required, which have high technical difficulty. Furthermore, the timing of retransplantation is usually suboptimal, given the shortage of DD and LD grafts and the urgency involved with the failing first liver graft. Fundamental requirements for improving retransplantation results include expanding the donor pool and having a proper timing of retransplantation.

Keywords: Living donor; Deceased donor; Graft failure; Chronic rejection; Primary nonfunction 


\section{INTRODUCTION}

Adult-to-adult living donor liver transplantation (LDLT) has been established as a successful alternative to help solve the serious shortage problem of deceased donor (DD) grafts. However, living donor (LD) liver retransplantation has been uncommonly performed in spite of a large number of adult-to-adult LDLTs. In the United States of America, a study using Adult to Adult Living Donor Liver Transplantation Study (A2ALL) data collected between 1998 and 2014 revealed that 110 recipients $(10.3 \%)$ of 1,065 patients underwent retransplantation, in which hepatitis $C$ virus infection, longer length of stay, hepatic artery thrombosis, biliary stricture, infection, and disease recurrence were associated with increased risk of retransplantation [1]. In a Japanese multicenter study, 7,937 liver transplants had been performed at 67 institutions by the end of 2014, with 7,673 LD and 264 DD liver transplants [2]. First transplantation was performed in 7,682 patients ( $96.8 \%)$, second transplantation in 242 patients (3.0\%), and third transplantation in 13 patients $(0.2 \%)$ [2].

At Asan Medical Center (AMC), retransplantation was performed in 126 (3.1\%) patients among 4,051 liver transplant recipients who underwent $\operatorname{LDLT}(n=3,431)$ or deceased donor liver transplantation (DDLT) $(n=626)$, between 1992 and 2013. Second retransplantation was performed in 117 patients, third retransplantation in 7 patients and fourth retransplantation in 2 patients. Common causes of retransplantation were immunologic complications (acute and chronic rejection) in $38(30.2 \%)$ patients, primary non-function or dysfunction in $23(18.3 \%)$ patients, biliary complications in $25(19.8 \%)$ patients, recurrence of primary disease in $20(15.9 \%)$ patients, and vascular complications in $20(15.9 \%)$ patients. In 109 adult patients who underwent retransplantation, 85 patients had initially undergone primary LDLT, and (15.3\%) patients received LD retransplant and 72 (84.7\%) patients received DD retransplant; and another 24 patients have initially undergone primary DDLT, and 4 (16.7\%) patients received LD retransplant and 20 (83.3\%) patients received DD retransplant. The interval period between the first and second transplantation was within 2 weeks in $20.0 \%, 2$ weeks to 1 month in $6.3 \%, 1$ month to 1 year in $44.2 \%$, and greater than 1 year in $29.5 \%$ of cases.

In contrast, the reported rate of retransplants from largevolume DD liver transplantation programs has varied from $7 \%$ to $23 \%$ [3]. In the University of California, Los Angeles, a series of 3,200 liver transplants (including 65 LDLTs) were performed; retransplantation was performed, sometimes more than once, in 538 (20.2\%) of 2,662 patients [4].

The primary reasons that adult LD retransplantation has such a low incidence compared to DD retransplantation are as follows: first, the incidence of primary nonfunction is very low after LD transplants (Fig. 1) [5-7]. Primary non-function is the most common cause of retransplantation after DD transplantation; second, the low incidence of $L D$ is related to the progressive decrease in the rates of graft failures from technical causes, due to advancement of surgical techniques and improvement of imaging studies for both donor and recipient hepatic vascular anatomy evaluations [8]. Various innovative surgical techniques have contributed to decrease the incidence of refractory surgical complications after LDLT. Hence, the need for retransplantation has proportionately decreased [9]; third, it is due to the definite shortage of available DD or LD liver grafts for retransplantation. In North America and Europe where DDLT is the main types of liver transplant, a DD liver graft could probably be available after a relatively short waiting time if an urgent retransplantation is required [5]. LD liver grafts are primarily used for the first liver transplantation to cope with the relative shortage of DD livers. The probability of using LD grafts for retransplantation is very low. Furthermore, the cumulative number of LDLTs in North America and Europe is much smaller than that in Asian countries. As a result, in North America and Europe, the experience of LDLT-associated liver retransplantation would be confined to LD-to-DD retransplantation. However, in Asian countries where DD liver grafts are in shortage, the probability of retransplantation with either DD or LD liver graft is very low because of the lack of donors. Thus, serious posttransplant complications often directly lead to death, without any chance of retransplantation.

\section{RETRANSPLANTATION ACCORDING TO DONOR TYPE}

LDLT-associated retransplantation can be classified into three types according (LD-to-LD, LD-to-DD, and DD-to-LD retransplantation) to the sequences of grafts used, because different surgical techniques should be considered according to different sequences. It is also classified into two types (early and late) according to the retransplantation timing like in ordinary DDLT [10].

After applying these combinations, early retransplantation from LDLT to DDLT might be the most typical type in countries where DD organs are available. It is also the simplest type of retransplantation because all structures 

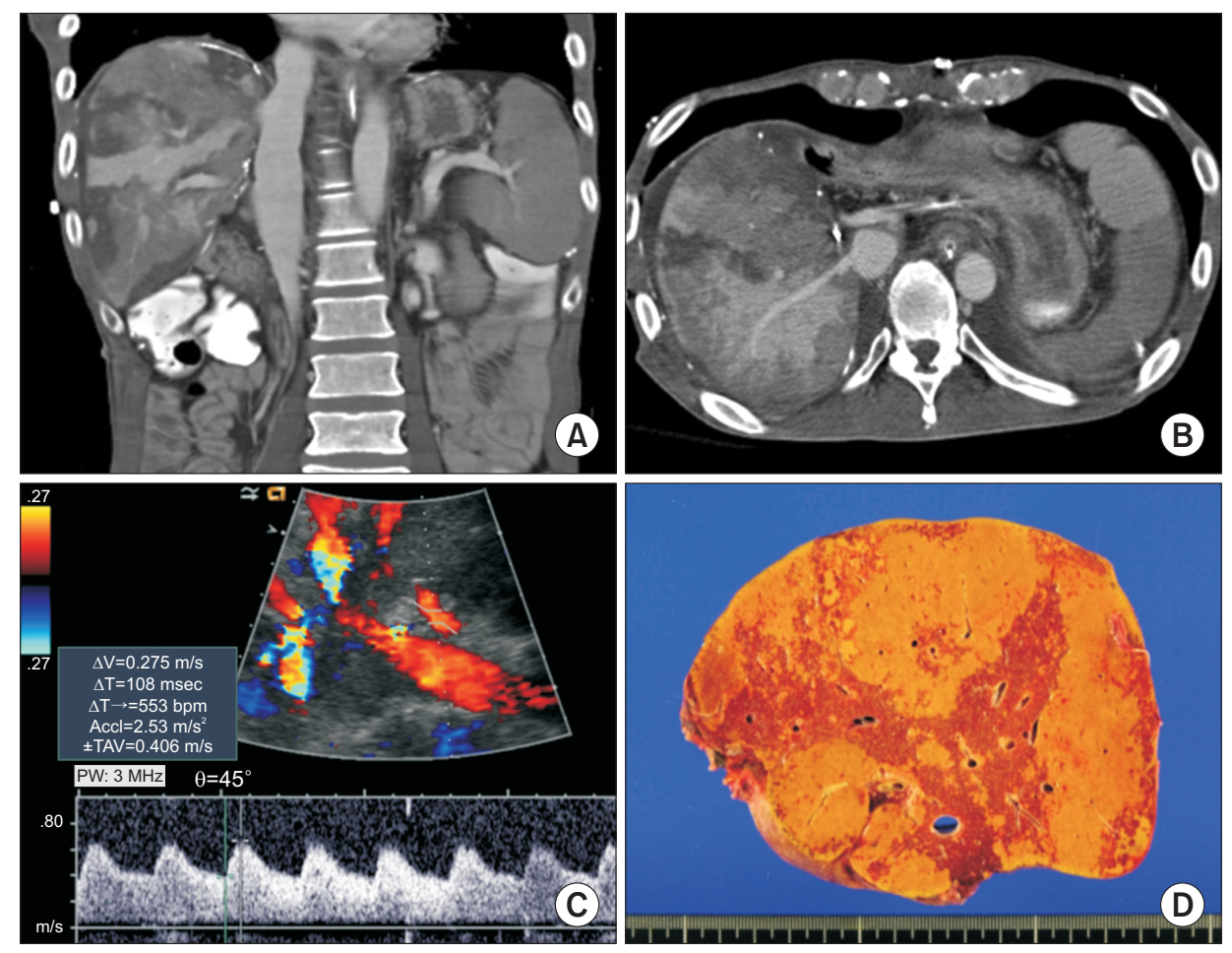

Fig. 1. Posttransplant findings of severe early graft dysfunction following living donor liver transplantation using a modified right liver graft. The liver graft shows extensive parenchymal infarct $(A, B)$ with intact inflow and outflow vessels (C). The explant liver shows massive coagulative necrosis (D).

belonging to the first liver graft would be removed before forming heavy adhesions and a new graft can be anastomosed to the recipient's native structures. On the other hand, late retransplantation to LDLT is possibly the worst combination because severe adhesions, distorted structures and newly developed collateral veins could make recipient operation very difficult or impossible (Fig. 2). In practice, retransplantation using a LD liver graft has a limited indication only for life-saving purpose.

The outcome of LDLT-associated retransplantation has not been reported yet in literature. Based on our experience of LDLT-associated retransplantation at AMC for 126 patients, the in-hospital mortality was $22.1 \%$, which was much higher than that of primary LT ( $4.8 \%$ of 3,925 patients). Posttransplant survival rate after retransplantation was $68.3 \%$ at 1 year, $61.2 \%$ at 3 years, and $58.5 \%$ at 5 years. The underlying cause of such relatively low survival rates might be inevitable delay in timing for retransplantation primarily due to donor factors.

\section{INCIDENCE AND INDICATIONS OF RETRANSPLANTATION}

It is presumed that only a small number of liver recipients have undergone LDLT-associated retransplantation
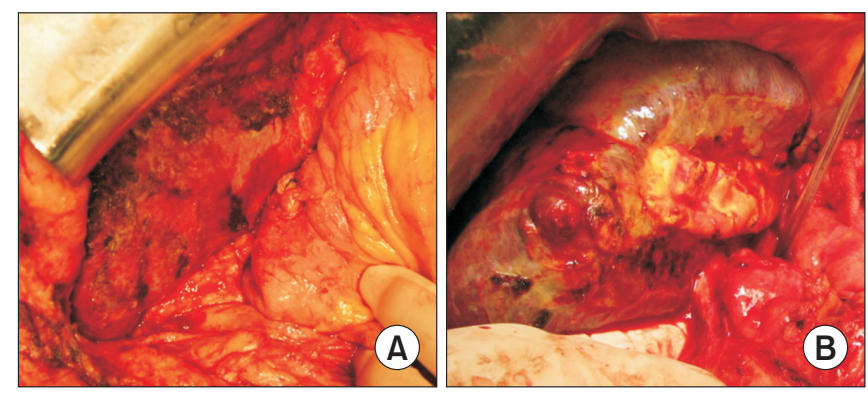

Fig. 2. Intraoperative photographs showing heavy adhesion around the liver graft. First living donor liver transplantation using a modified right liver graft was performed 7 years (A) and 5 years (B) before.

worldwide to date. A LD liver graft can be used for the first or second liver transplantation. The timing of retransplantation also should be stratified into two types as early and late. Combination of these two classifications results in six types of LDLT-associated retransplantation. However, to the best of our knowledge, late retransplantation to LDLT might have been rarely performed in most LDLT programs worldwide. Considering our limited experience on late LD retransplantation after initial LDLT, it does not seem to be reasonable or sometimes is not feasible to dissect heavy adhesions around the initial partial liver graft, especially at the conglomerated hilar structures, to make them suitable 
for LDLT. Thus, the other five types of LDLT-associated retransplantation were taken into account.

The most typical type of LDLT-associated retransplantation is early LD-to-DD retransplantation. Any cause of early graft failure can be indicated for this type of retransplantation if a DD organ is available. It includes primary nonfunction, severe early graft dysfunction, and major surgical complications confined to the liver graft, similar to those of DDLT. Although the incidence of primary nonfunction following LDLT has been sporadically commented in the literature, the actual incidence is unknown so far after exclusion of technical factors during the learning curve of LDLT (Fig. 1) [5-7]. According to our experience at AMC, its incidence was definitely less than $1 \%$ if strict definition of primary non-function was applied. Severe early graft dysfunction of the LD liver grafts was often associated with small-forsize graft syndrome, excessive venous congestion of the right liver graft from graft hepatic vein outflow obstruction, or portal flow steal syndrome. Serious hepatic artery-related complications including hepatic artery thrombosis occurred in $1-5 \%$ at large-volume LDLT centers. They are the leading causes of early graft failure following LDLT [11-13]. Intractable biliary complication also can be an indication of retransplantation because its clinical course could be intractable and it occasionally can induce life-threatening sepsis [14]. If the general condition of a patient allows the patient to endure the retransplantation procedure, there might be no absolute contraindication specific for this type of retransplantation. Thus, LD-to-DD retransplantation shares the same retransplantation indication criteria with initial DDLT.

For early LD-to-LD retransplantation, its eligibility criteria might be similar to those of early LD-to-DD retransplantation. However, its technical feasibility should be considered first. The most important point is the availability of hepatic arterial blood flow source (Fig. 3). One of the reliable arterial flow sources other than the proper hepatic artery is the right gastroepiploic artery because it can be easily mobilized toward the hepatic hilum after detachment from the stomach and can be promptly enlarged to facilitate size matching (Fig. 4). The clinical significance of the right gastroepiploic artery and its use for LDLT have been well proven in the literature $[11,12,15]$. A cold-stored fresh arterial vessel homograft recovered from a deceased organ donor should be sought for arterial interposition or jump graft.

For early DD-to-LD retransplantation, its indications are exactly the same as those for the aforementioned LD-to-LD retransplantation unless extensive hepatic artery throm-
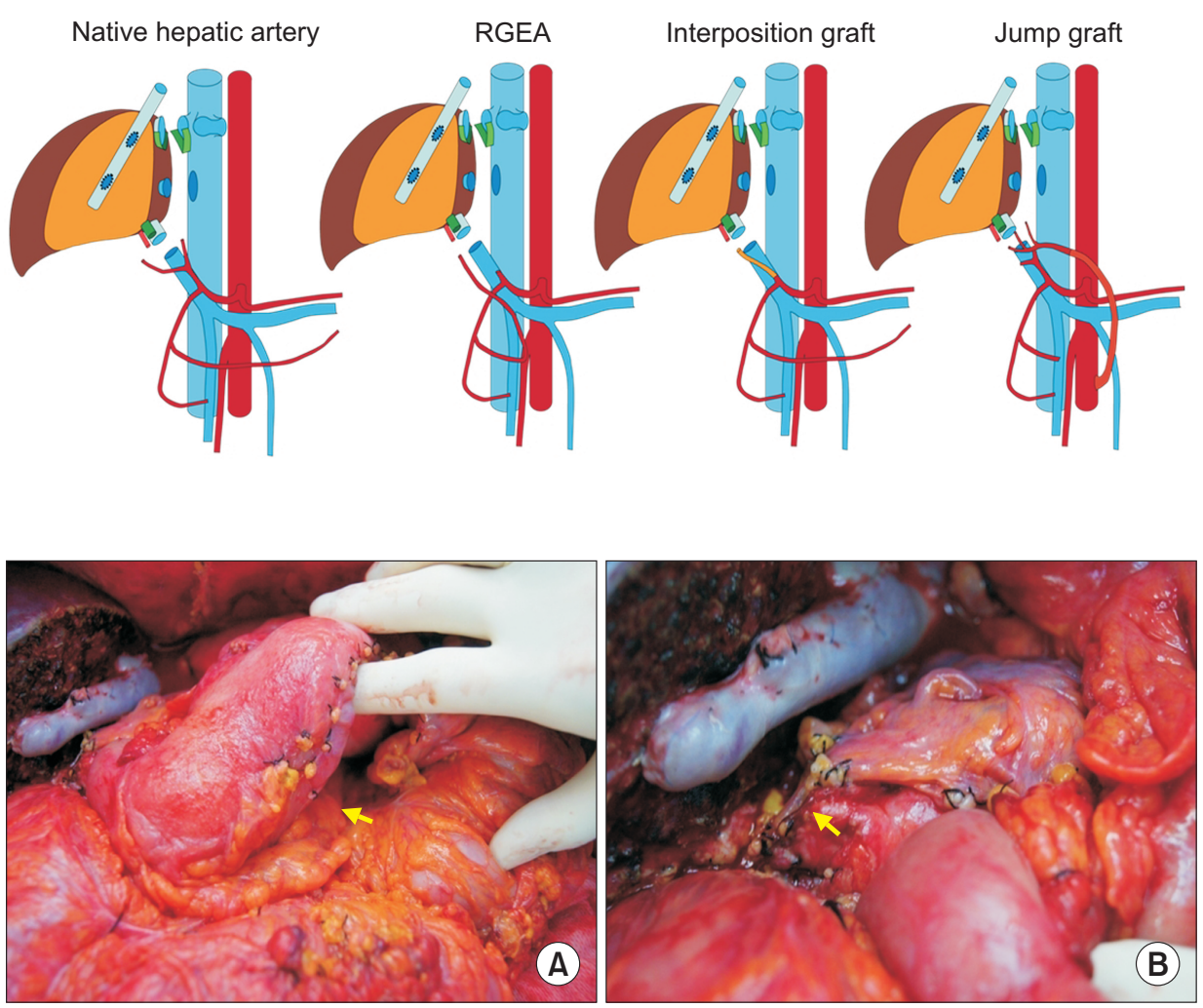

Fig. 3. Schematic illustration showing various sources of the hepatic artery inflow used for living donor liver transplantation using a right liver graft. RGEA indicates the right gastroepiploic artery. 
bosis has occurred. Hilar dissection of a failed whole liver graft is comparable to that of liver dissection during initial LDLT. If hepatic arterial thrombosis was the cause of graft failure, an alternative arterial flow source such as the right gastroepiploic artery should be searched first.

Late DD retransplantation after initial LDLT has the same indication as that for ordinary late DD retransplantation, such as recurrence of hepatitis $C$ cirrhosis or chronic rejection. This type of retransplantation carries an increased risk than DD-to-DD retransplantation [16-19]. As there is no short-cut to dissect heavy adhesions, the timing of DD and recipient operations should be adequately adjusted so that cold preservation time is not prolonged too much $[20,21]$.

\section{TECHNICAL CONSIDERATIONS FOR LDLT-ASSOCIATED RETRANSPLANTATION}

The difficulty of recipient operation usually depends on the timing of the retransplantation. Early emergency retransplantation such as retransplantation within the first week does not require difficult dissection process because there is little adhesion around the liver graft. Retransplantation after an interim period such as 1-3 months would make adhesions from mild degree to severe degree. Although minute collateral vasculatures are not usually developed in the adhesion of this time, meticulous sharp dissection is mandatory to secure the dissection effectively. For late retransplantation after progression of viral hepatitis or chronic rejection, heavy adhesions and new development of portal venous collaterals would be encountered. Every adhesion should be cut sharply and every bleeding point should be strictly controlled during the dissection process. Rough blunt dissection of such adhesion should be avoided because it can induce massive uncontrollable bleeding from the widely dissected surface in a situation of portal hypertension. Except for early retransplantation, retrans- plantation operation usually takes much longer operation time for dissection than in the initial operation. Thus, experience-based adjustment of scheduling for donor and recipient operations is important so that cold preservation time or LD operation time would not be prolonged $[20,21]$.

\section{Early LD-to-DD Retransplantation}

After the main operative wound for the initial LDLT is opened, gentle blunt dissection with fingers would make the gelatinous or mild adhesion separate from the liver graft. Hepatic hilar structures should be manipulated gently, but the hepatic artery and the common bile duct may not be suitable for reuse in DD retransplantation. Retrohepatic inferior vena cava should be dissected further especially the cephalad to enable a deep secure clamping of the suprahepatic vena cava over the diaphragm because hepatic vein cuffs are nearly absent. As the cephalad end of the right hepatic vein orifice is located very close to the diaphragm, deep diaphragm clamping is mandatory to secure suprahepatic vena cava anastomosis (Fig. 5). In this type of retransplantation, the common hepatic artery may not be suitable for arterial anastomosis. Adequate branch patch cannot be made because all branches other than the previously anastomosed branch are ligated already. Blood outflow from the right gastroepiploic artery often appears to be too small to perfuse the whole liver graft reliably. Thus, performance of an arterial graft interposition should be taken into account. An infrarenal aortic jump graft is preferred over a supraceliac aortic graft. After complete dissection of the old graft and inferior vena cava, retransplantation is performed according to routine procedures like in DD-to-DD retransplantation. Primary LDLT often uses duct-to-duct anastomosis, so the condition of the recipient bile duct is usually not good enough to re-do duct anastomosis. Thus, Roux-en-Y choledochojejunostomy is usually used $[22,23]$.

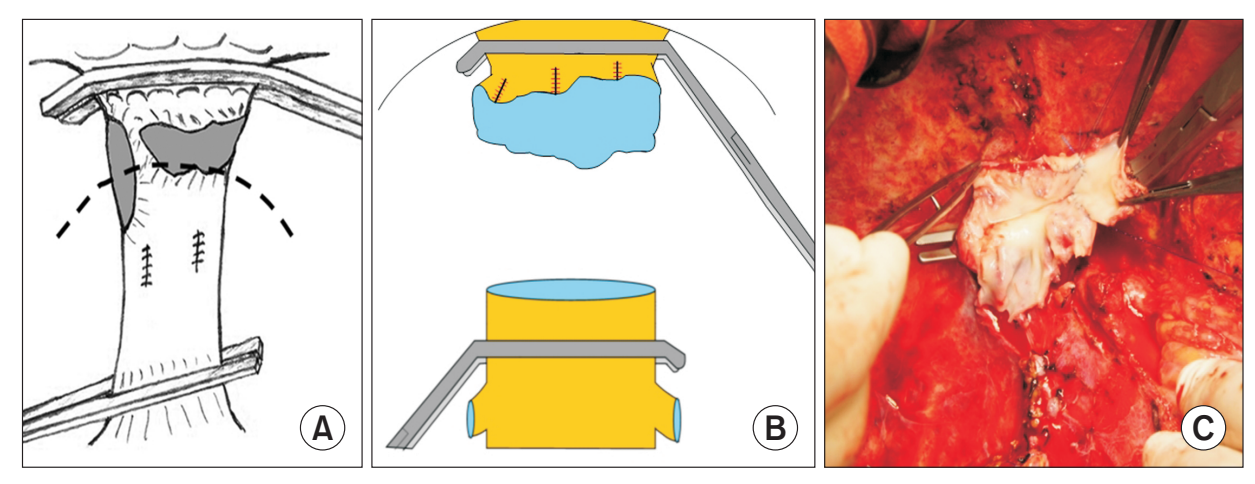

Fig. 5. Images showing preparation of the recipient inferior vena cava (IVC) for deceased whole liver retransplantation after initial living donor liver transplantation. (A) The failed liver graft is completely removed and the supra- and infrahepatic IVC stumps are deeply clamped. (B) Relatively long IVC stumps are left. (C) The hepatic vein stumps at the suprahepatic IVC stump are unified to be suitable for anastomosis. 


\section{Early LD-to-LD Retransplantation}

For early LD-to-LD retransplantation, the type of the second liver graft and the hepatic arterial inflow source should be considered prudently. As this retransplantation is usually performed in a highly morbid situation, a suboptimal donor graft such as a graft size smaller than $40 \%$ of the recipient's standard liver volume or a graft-to-recipient weight ratio less than 0.8 should not be used considering the severity of peritransplant conditions [24-26]. DD livers with variant liver anatomy such as variant portal vein or hepatic artery should not be used [11-13,27,28]. If a right liver graft is used, hepatic venous congestion should be minimized through vessel interposition reconstruction or concurrent procurement of the middle hepatic vein trunk [29-32]. Arterial flow source is another important point that should be considered before this type of retransplantation because it is usually not feasible to use a proper hepatic arterial branch again even in under favorable situations in the absence of hepatic artery thrombosis. The splenic artery is usually unsuitable for arterial reconstruction of LDLT due to its limited length and diameter discrepancy. It is not preferred to use a cryopreserved artery graft for small- or medium-sized arterial reconstruction due to a high risk of arterial thrombosis or potential pseudoaneurysm formation although successful outcomes have been sporadically reported [33-35]. Instead, fresh cold-stored arterial grafts from deceased donors can be used like in primary LDLT for recipients with destructed hepatic artery (Fig. 3). For such purpose, it is reasonable to procure a superior mesenteric artery homograft from a deceased donor during procurement of iliac artery grafts because the superior mesenteric artery has many small branches matching to the right or left hepatic artery of a partial liver graft. Another reliable source of hepatic arterial flow is the right gastroepiploic artery (Fig. 4). In practice, in a situation requiring an arterial blood flow source other than innate hepatic arteries, the right gastroepiploic artery has been the most preferable artery for LDLT because of its invariable anatomical location, expandible size, and long length. This artery often looks too small at a glance, but it can be rapidly enlarged after clamping for a short time. As this artery is fed from the arterial arcades at the pancreatic head not to mention of the gastroduodenal artery, the usual hepatic artery thrombosis without extension to the celiac axis usually does not have negative influence on its blood flow. These merits of the right gastroepiploic artery as a reliable substitute source for hepatic arterial flow have led to its use for multiple or re-do arterial reconstruction in LDLT. Preoperative selective arteriography and three-dimensional reconstruction of dynamic computed tomographic angiography can be used for its preoperative evaluation [36].

To remove the old graft and secure anastomosis of the hepatic vein, deep secure suprahepatic vena cava clamping over the diaphragm should be prepared like in DD retransplantation (Fig. 6). As prolonged vena cava clamping is often required, active venovenous bypass would be beneficial to maintain vital signs and prevent splanchnic congestion. After complete dissection of the old graft and inferior vena cava, the retransplantation procedure proceeds routinely as in primary LDLT. Portal vein should be cut close to the old liver graft across the anastomotic line, and suture material is then removed. Similar principle would be applied to the hepatic vein orifice. After inferior vena cava clamping, the liver parenchyma should be cut to leave some tissue at the hepatic vein orifice. After that, suture material should be removed to preserve the edge of the hepatic vein orifice intact. Technically, the use of a partial graft of the same type is of advantage for intra-abdominal space positioning and hepatic vein reconstruction. The same stump of portal vein can be used for portal vein reconstruction. Hepatic vein stump can be used like in primary LDLT. When using the right gastroepiploic artery as an alternative hepatic arterial flow source, it is necessary to straighten the anastomosis site not to make a kinking deformity. To avoid accidental excessive tension at the arterial anastomosis site, it is beneficial to transfix the artery to the surrounding structure such as the gastric antrum before performing other procedures. The recipient bile duct which had been used for biliary reconstruction is not acceptable for duct-to-duct

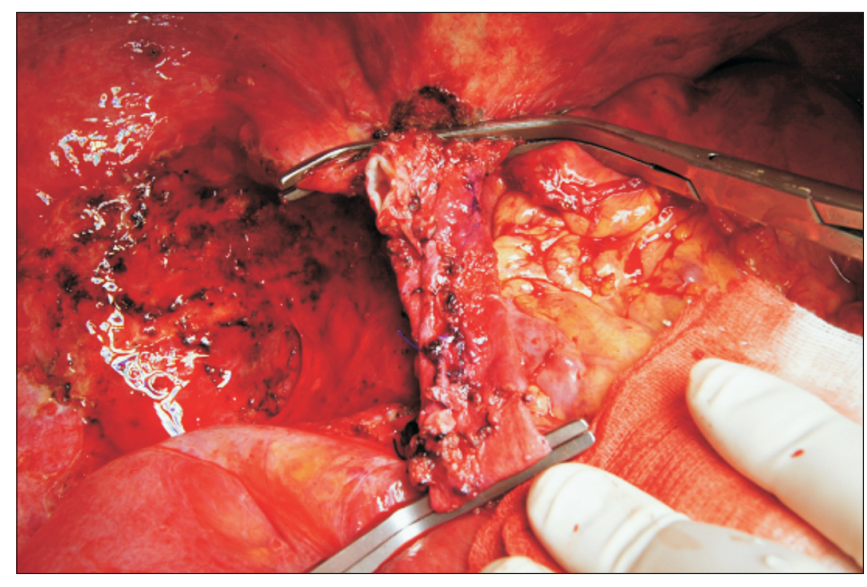

Fig. 6. Intraoperative photograph showing deep total clamping of the retrohepatic inferior vena cava. 
anastomosis, thus Roux-en-Y hepaticojejunostomy is mandatory.

\section{Early DD-to-LD Retransplantation}

This type of retransplantation has been usually applied to primary non-function of the first DD liver graft. Thus, all vascular structures should remain intact. In contrast, if the cause of first graft failure is vascular complication such as hepatic artery thrombosis, portal vein stenosis or vena cava stenosis, such patient may not be indicated for this type of retransplantation. Any type of LD liver graft can be implanted like first LDLT. However, a right lobe graft is desirable due to stable settlement of the partial liver graft in the right subphrenic fossa. Hilar vascular structures and retrohepatic inferior vena cava of the failed liver graft should be dissected like in primary LDLT (Fig. 7). The inferior vena cava and portal vein of the first graft should be left as interposition grafts. The hepatic artery of the first graft can be used as an interposition graft, or other sources of arterial blood flow such as gastroepiploic artery can be used alternatively. Since the retrohepatic inferior vena cava should be fully preserved, both supra- and infrahepatic anastomotic lines should be protected carefully. The portal vein of the first graft should be dissected, but this process is not difficult because the failed liver has nearly normal consistency and hilar structures are dissected already. It

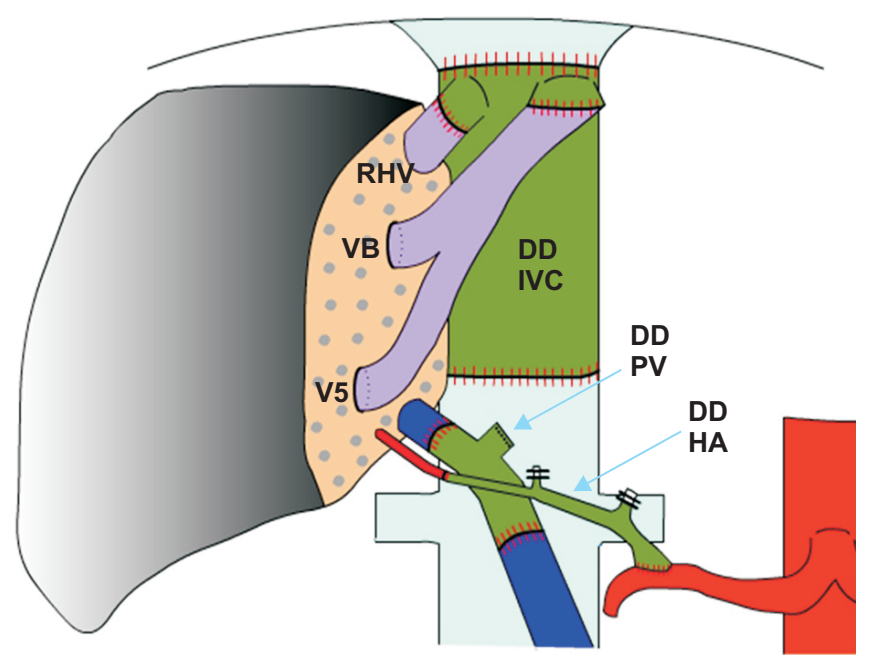

Fig. 7. Schematic illustration showing early retransplantation using a modified right liver graft after deceased donor whole liver transplantation. The interposed vessels originated from the deceased donor (DD) graft included the retrohepatic inferior vena cava (IVC), main portal vein (PV) and hepatic artery (HA). RHV, V5 and V8 indicate the right hepatic vein, segment $\mathrm{V}$ hepatic vein and segment VIII hepatic vein, respectively. is not recommended to use the hepatic artery branch of the first graft [3], although its use might be not worse than using other types of jump graft. Based on our experience at AMC, such an arterial interposition did not result in any arterial complication. Alternatively, the right gastroepiploic artery can be used as an arterial flow source without interposition of DD graft artery. Duct-to-duct anastomosis is not feasible because the proximal portion of the recipient bile duct had already been removed during the first transplant operation. There is no choice of biliary reconstruction other than Roux-en-Y hepaticojejunostomy.

\section{Late LD-to-LD Retransplantation}

It is almost impractical to perform this type of retransplantation because of heavy adhesion and distorted hilar structures that do not permit sufficient dissection. The native hepatic vein, portal vein and hepatic artery cannot be not used, thus various patch venoplasty and vessel interposition are necessary for graft implantation (Fig. 8). If another source of hepatic artery inflow is not available, an aortic jump graft with a fresh cold-stored DD iliac artery can be used for hepatic arterial reconstruction (Fig. 9).

\section{Late LD-to-DD Retransplantation}

Heavy adhesion and prominent venous collateral could be encountered during recipient operation (Fig. 2). Piggy-

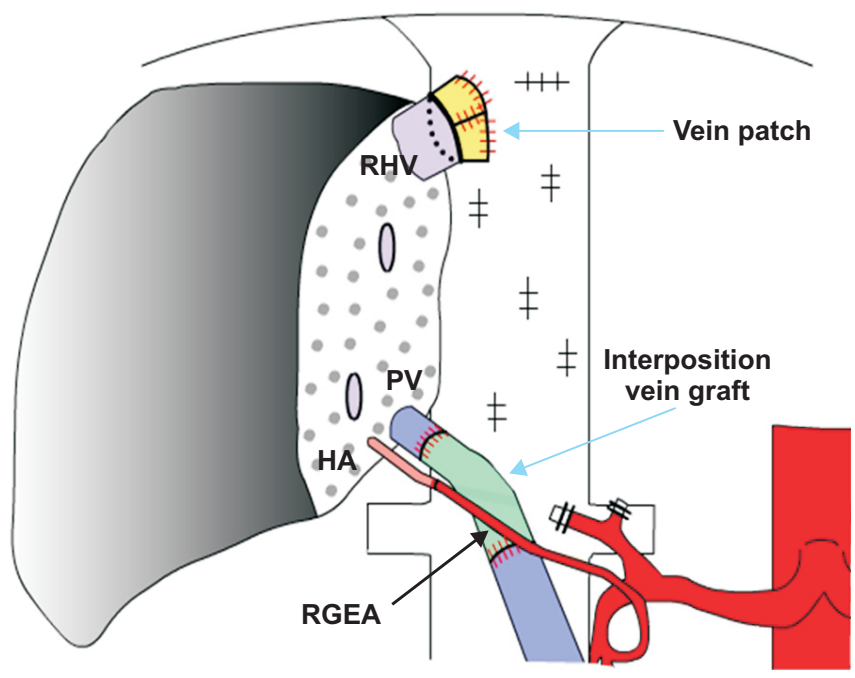

Fig. 8. Schematic illustration showing late retransplantation using a modified right liver graft after living donor liver transplantation. The right hepatic vein (RHV) stump is newly made with vein patch venoplasty. The portal vein (PV) is interposed with a large-caliber vein graft. The right gastroepiploic artery (RGEA) is used for hepatic artery (HA) reconstruction. 


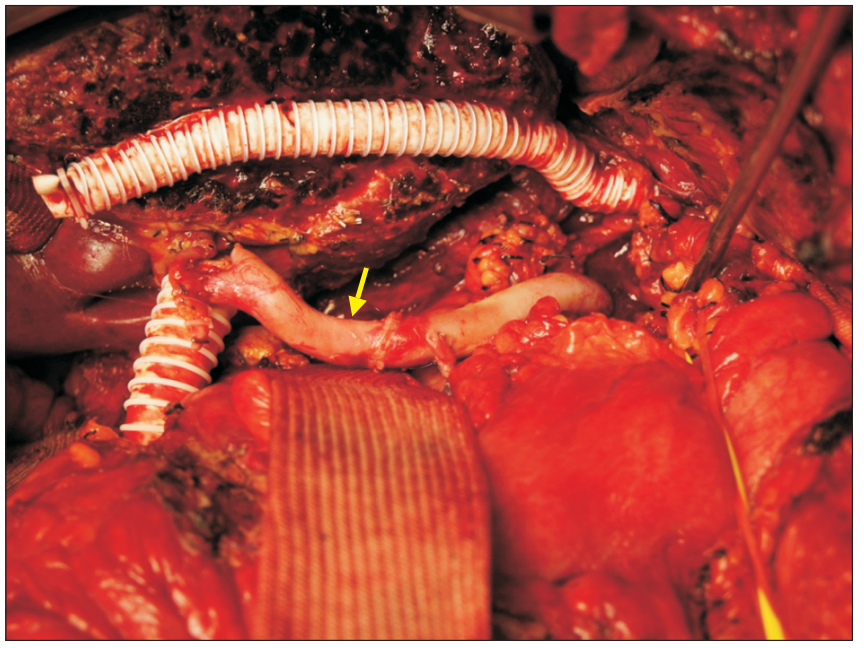

Fig. 9. Intraoperative photograph showing an aorto-hepatic jump graft during retransplantation using a modified right liver graft. Arrow indicates an interposed iliac artery homograft.

back technique may not be feasible, thus it is not recommended due to heavy adhesions around the retrohepatic inferior vena cava. Dissection of the main portal vein which had been once dissected would require meticulous sharp dissection. A common hepatic artery patch or an aortic jump graft is used for hepatic arterial reconstruction. There is no choice other than Roux-en-Y choledochojejunostomy.

\section{Late DD-to-LD Retransplantation}

This type of retransplantation is also the least recommended type like late LD-to-LD retransplantation. Surgical technique would be similar to that of early DD-to-LD retransplantation. However, the difficulty of hilar dissection varies depending on patient conditions, especially regarding portal hypertension and perihepatic collateral development.

\section{OUTCOME OF LDLT-ASSOCIATED RETRANSPLANTATION}

Since LDLT-associated retransplantation has been performed in a small number of patients worldwide, its outcome cannot be assessed statistically unlike in DD retransplantation. Furthermore, LDLT itself indicates shortage of DD organs, thus optimal retransplantation timing might have been missed for the majority of patients with a failing first liver graft. Considering the real-world situation of DD organ shortage and limited availability of LDs, the outcome of LDLT-associated retransplantation might be naturally worse than that of DD retransplantation. Although DD re- transplantation has higher morbidity and lower survival than primary DDLT, the 1-year survival in adult recipients has been reported to be about $70 \%$ in the literature $[16,37]$. Considering the disadvantageous situation of LDLT-associated retransplantation, the 1-year survival of $68.3 \%$ from our AMC series was comparable to that of DD retransplantation. Late DD retransplantation has been often performed for patients with hepatitis $C$ virus reinfection, and this disease was associated with lower patient and graft survival than retransplantation due to other causes [38].

\section{CONCLUSIONS}

Because LDLT-associated retransplants have been performed in only a small number of recipients worldwide, their outcomes cannot be assessed objectively. However, it is reasonable to expect that it has an inferior outcome to DD-to-DD retransplantation. There are several LDLT-associated technical limitations. Procurement of LD liver grafts with long vascular stumps is not allowed, thus alternative methods of vascular reconstruction are often required, which have high technical difficulty. Furthermore, the timing of retransplantation is usually suboptimal and often delayed, given the shortage of DD and LD grafts and the urgency involved with a failing first liver graft. Despite marked technical advances in LDLT, LD retransplants still carry high overall morbidity and mortality. Fundamental requirements for improving retransplantation results include expanding the donor pool and having a proper timing of retransplantation.

\section{FUNDING}

This study received no funding.

\section{CONFLICT OF INTEREST}

All authors have no conflicts of interest to declare.

\section{ORCID}

Deok-Bog Moon https://orcid.org/0000-0002-8209-3540 Shin Hwang https://orcid.org/0000-0002-9045-2531 Chul-Soo Ahn https://orcid.org/0000-0002-3844-3646 Tae-Yong Ha https://orcid.org/0000-0001-9932-0212 Gi-Won Song https://orcid.org/0000-0002-4235-0434 Dong-Hwan Jung https://orcid.org/0000-0001-5984-023X Gil-Chun Park https://orcid.org/0000-0003-1631-3258 


\section{AUTHORS' CONTRIBUTIONS}

Conceptualization: SH. Data curation: DBM, CSA. Methodology: TYH, GWS, DHJ, GCP. Visualization: SH, DBM. Writing - original draft: $\mathrm{SH}$, DBM. Writing - review \& editing: All.

\section{REFERENCES}

1. Braun HJ, Grab JD, Dodge JL, Syed SM, Roll GR, Schwab MP, et al. Retransplantation after living donor liver transplantation: data from the adult to adult living donor liver transplantation study (A2ALL). Transplantation 2020. [Epub ahead of print]

2. Kuramitsu K, Fukumoto T, Egawa H, Ohdan H, Umeshita K, Uemoto $S$, et al. A multicenter Japanese survey assessing the long-term outcomes of liver retransplantation using living donor grafts. Transplantation 2020;104:754-761.

3. Lerner SM, Markmann J, Jurim O, Busuttil RW. Retransplantation. In: Busuttil RW, Klintmalm GB, eds. Transplantation of the liver. 2nd ed. Philadelphia: Saunders, 2005:767-775.

4. Busuttil RW, Farmer DG, Yersiz H, Hiatt JR, McDiarmid SV, Goldstein LI, et al. Analysis of long-term outcomes of 3200 liver transplantations over two decades: a single-center experience. Ann Surg 2005;241:905-916; discussion 916-918.

5. Olthoff KM, Merion RM, Ghobrial RM, Abecassis MM, Fair JH, Fisher RA, et al.; A2ALL Study Group. Outcomes of 385 adultto-adult living donor liver transplant recipients: a report from the A2ALL Consortium. Ann Surg 2005;242:314-323, discussion 323-325

6. Hwang S, Lee SG, Lee YJ, Park KM, Choi DN, Ahn CS, et al. A case of primary non-function following adult-to-adult living donor liver transplantation. Hepatogastroenterology 2002;49: 1412-1414.

7. Colombani PM, Lau H, Prabhakaran K, Maley W, Wise B, Schwarz K, et al. Cumulative experience with pediatric living related liver transplantation. J Pediatr Surg 2000;35:9-12.

8. Sugawara $Y$, Makuuchi M. Advances in adult living donor liver transplantation: a review based on reports from the 10th anniversary of the adult-to-adult living donor liver transplantation meeting in Tokyo. Liver Transpl 2004;10:715-720.

9. Moon DB, Lee SG. Adult-to-adult living donor liver transplantation at the Asan Medical Center. Yonsei Med J 2004;45:11621168.

10. Hwang S, Ahn CS, Kim KH, Moon DB, Ha TY, Song GW, et al. Liver retransplantation for adult recipients. Korean J Hepatobiliary Pancreat Surg 2013;17:1-7.

11. Ahn CS, Lee SG, Hwang S, Moon DB, Ha TY, Lee YJ, et al. Anatomic variation of the right hepatic artery and its reconstruc- tion for living donor liver transplantation using right lobe graft. Transplant Proc 2005;37:1067-1069.

12. Ahn CS, Hwang S, Moon DB, Song GW, Ha TY, Park GC, et al. Right gastroepiploic artery is the first alternative inflow source for hepatic arterial reconstruction in living donor liver transplantation. Transplant Proc 2012;44:451-453.

13. Wei WI, Lam LK, Ng RW, Liu CL, Lo CM, Fan ST, et al. Microvascular reconstruction of the hepatic artery in live donor liver transplantation: experience across a decade. Arch Surg 2004; 139:304-307.

14. Hwang S, Lee SG, Sung KB, Park KM, Kim KH, Ahn CS, et al. Long-term incidence, risk factors, and management of biliary complications after adult living donor liver transplantation. Liver Transpl 2006;12:831-838.

15. Itabashi Y, Hakamada K, Narumi S, Toyoki Y, Totsuka E, Umehara $Y$, et al. A case of living-related partial liver transplantation using the right gastroepiploic artery for hepatic artery reconstruction. Hepatogastroenterology 2000;47:512-513.

16. Yao FY, Saab S, Bass NM, Hirose R, Ly D, Terrault N, et al. Prediction of survival after liver retransplantation for late graft failure based on preoperative prognostic scores. Hepatology 2004;39:230-238.

17. Burton JR Jr, Sonnenberg A, Rosen HR. Retransplantation for recurrent hepatitis $C$ in the MELD era: maximizing utility. Liver Transpl 2004;10(10 Suppl 2):S59-S64.

18. Burton JR Jr, Rosen HR. Liver retransplantation for hepatitis $C$ virus recurrence: a survey of liver transplant programs in the United States. Clin Gastroenterol Hepatol 2005;3:700-704.

19. Zimmerman MA, Ghobrial RM. When shouldn't we retransplant? Liver Transpl 2005;(11 Suppl 2):S14-S20.

20. Schnitzler MA, Woodward RS, Brennan DC, Whiting JF, Tesi RJ, Lowell JA. The economic impact of preservation time in cadaveric liver transplantation. Am J Transplant 2001;1:360365.

21. Totsuka E, Fung JJ, Lee MC, Ishii T, Umehara M, Makino $Y$, et al. Influence of cold ischemia time and graft transport distance on postoperative outcome in human liver transplantation. Surg Today 2002;32:792-799.

22. Nakamura N, Nishida S, Neff GR, Vaidya A, Levi DM, Kato T, et al. Intrahepatic biliary strictures without hepatic artery thrombosis after liver transplantation: an analysis of 1,113 liver transplantations at a single center. Transplantation 2005;79: 427-432.

23. Schlitt HJ, Meier PN, Nashan B, Oldhafer KJ, Boeker K, Flemming $P$, et al. Reconstructive surgery for ischemic-type lesions at the bile duct bifurcation after liver transplantation. Ann Surg 1999;229:137-145.

24. Shimada M, ljichi H, Yonemura Y, Harada N, Shiotani S, Ni- 
nomiya $\mathrm{M}$, et al. Is graft size a major risk factor in living-donor adult liver transplantation? Transpl Int 2004;17:310-316.

25. Kiuchi T, Tanaka K, Ito T, Oike F, Ogura Y, Fujimoto $Y$, et al. Small-for-size graft in living donor liver transplantation: how far should we go? Liver Transpl 2003;9:S29-S35.

26. Ito T, Kiuchi T, Yamamoto H, Oike F, Ogura Y, Fujimoto $Y$, et al. Changes in portal venous pressure in the early phase after living donor liver transplantation: pathogenesis and clinical implications. Transplantation 2003;75:1313-1317.

27. Marcos A, Orloff M, Mieles L, Olzinski A, Sitzmann J. Reconstruction of double hepatic arterial and portal venous branches for right-lobe living donor liver transplantation. Liver Transpl 2001;7:673-679.

28. Lee SG, Hwang S, Kim KH, Ahn CS, Park KM, Lee YJ, et al. Approach to anatomic variations of the graft portal vein in right lobe living-donor liver transplantation. Transplantation 2003; 75(3 Suppl):S28-S32.

29. Lee SG, Park KM, Hwang S, Kim KH, Choi DN, Joo SH, et al. Modified right liver graft from a living donor to prevent congestion. Transplantation 2002;74:54-59.

30. Hwang S, Lee SG, Park KM, Kim KH, Ahn CS, Lee YJ, et al. Hepatic venous congestion in living donor liver transplantation: preoperative quantitative prediction and follow-up using computed tomography. Liver Transpl 2004;10:763-770.

31. Chan SC, Lo CM, Liu CL, Wong Y, Fan ST, Wong J. Tailoring donor hepatectomy per segment 4 venous drainage in right lobe live donor liver transplantation. Liver Transpl 2004;10:755762.

32. Hwang S, Lee SG, Choi ST, Moon DB, Ha TY, Lee YJ, et al. Hepatic vein anatomy of the medial segment for living donor liver transplantation using extended right lobe graft. Liver Transpl 2005;11:449-455.

33. Vivarelli M, Cavallari A, Buzzi M, Conte R. Successful arterial revascularization in liver transplantation using a cryopreserved arterial allograft. Transplantation 2004;77:792.

34. Kuang AA, Renz JF, Ferrell LD, Ring EJ, Rosenthal P, Lim RC, et al. Failure patterns of cryopreserved vein grafts in liver transplantation. Transplantation 1996;62:742-747.

35. Settmacher U, Steinmüller T, Luck W, Eisele R, Theruvath $T$, Heise $\mathrm{M}$, et al. Complex vascular reconstructions in living donor liver transplantation. Transpl Int 2003;16:742-747.

36. Lee SS, Kim TK, Byun JH, Ha HK, Kim PN, Kim AY, et al. Hepatic arteries in potential donors for living related liver transplantation: evaluation with multi-detector row CT angiography. Radiology 2003;227:391-399.

37. Postma R, Haagsma EB, Peeters PM, van den Berg AP, Slooff MJ. Retransplantation of the liver in adults: outcome and predictive factors for survival. Transpl Int 2004;17:234-240.

38. Yoo HY, Maheshwari A, Thuluvath PJ. Retransplantation of liver: primary graft nonfunction and hepatitis $C$ virus are associated with worse outcome. Liver Transpl 2003;9:897-904. 